\title{
Ficciones y fricciones sobre imaginarios del mundo rural: los Andes en Los perros hambrientos de Luis Figueroa
}

\author{
Mónica Delgado \\ (Universidad Nacional Mayor de San Marcos)
}

Recibido: 15/9/2016

Aprobado: 27/11/2016

\begin{abstract}
Resumen. A diferencia de otros filmes del cine peruano, en los que los Andes aparecen como un territorio de tránsito, del cual hay que huir, en Los perros hambrientos (1976), del cineasta peruano Luis Figueroa, se propone al campo y las montañas como entorno real de posibilidad y de resistencia ante la prepotencia del hacendado. Si bien difiere dramáticamente de lo esbozado en la novela de Ciro Alegría, Luis Figueroa encuentra en la narrativa el insumo necesario para mostrar la decadencia moral del latifundista, abandonar la nostalgia bucólica y la parábola animal del texto, y adentrarse en la dicotomía salvaje del hombre rico-hombre pobre, campesino versus hacendado.
\end{abstract}

Palabras clave: comunidades conocidas / cine sobre el mundo rural / cine pervano

\section{Fiction and Friction on Imaginaries of the Rural World: the Andes in Luis Figueroa's Los perros hambrientos}

Abstract. As opposed to other Peruvian films, where the Andes appear showcased as a transit territory which must be fled, in Los Perros Hambrientos (1976), Cuzquean filmmaker Luis Figueroa shares a view of the mountains and fields as a political place of possibility and resistance against the landowner's arrogance. While it dramatically differs from the original novel by Ciro Alegría, it also finds in the text the necessary basis to show the moral decadence of the landowner, to abandon the bucolic nostalgia and the animal parable of the text, and submerge itself in the savage dichotomies of rich man / poor man and peasant versus landowner.

Keywords: knowable communities / films about rurality / peruvian cinema 
$\mathrm{A}^{\mathrm{b}}$ lo largo de toda su historia, en la mayoría de filmes peruanos los Andes han aparecido como una simple locación. Sin embargo, hay contadas películas en las que la sierra escapa de ser un espacio de tránsito, un decorado, una atracción turística o una zona de la cual es urgente huir. En un puñado de películas realizadas entre 1977 y 1982 se puede detectar un uso distinto del territorio, vinculado a una necesidad por confrontar una problemática social persistente pos reforma agraria. Tanto en Los perros hambrientos (1976), Yawar Fiesta (1979) de Luis Figueroa o Laulico (1979) y Kuntur Wachana de Federico García, los Andes configuran o determinan la naturaleza humana y se convierten en un elemento que condiciona el designio o la suerte de modo tan marcado como lo fue el sertão para el Cinema Novo brasileño.

A diferencia de Kukuli (1960) de Luis Figueroa, donde por primera vez en el cine peruano se plasma un imaginario ficcional sobre lo indio y andino desde los mitos y las festividades para ir construyendo una propuesta de lo nacional a pesar de su telurismo, en Los perros hambrientos, el filme que abordo para indagar sobre las características de un cine peruano sobre el mundo rural, el campo aparece como una entidad que asfixia tanto como la mezquindad de los hacendados. El argumento gira en torno al conflicto entre campesinos y gamonales en tiempos de sequía, a mediados de los años treinta del siglo pasado, y cuya problemática es representada por el sino de una manada de perros de la comunidad rural, que sufre simbólicamente los mismos avatares humanos ante la opresión.

La intención de llevar a la pantalla grande una película de ascendencia indigenista y que está ambientada en periodos anteriores a la reforma agraria se debió al compromiso ético y político de denunciar una realidad que no había cambiado nada pese a las acciones del gobierno de Juan Velasco Alvarado. Una motivación por visibilizar un Estado que seguía manteniendo a los campesinos en la misma pobreza.

La hipótesis que planteo en este texto es que en la película Los perros hambrientos los Andes condicionan per se una existencia trágica y que no se puede transformar: la pobreza del campesino, comunero o indio no es producto de su marginación o de su ubicación olvidada dentro del sistema político y social (que se supone es la intención del cineasta), sino que se ve marcada por las contingencias del clima o de un destino implacable y divino. Una sequía expande la pobreza y polariza más las distancias con los hacendados, dueños reales de los Andes. El cuestionamiento político o social, o la responsabilidad misma del Estado, lucen secundarios ante el efecto de la sequía y dentro de un relato que utiliza metáforas de animales. Hay un determinismo que mantiene el status quo y que parte de esta lectura sobre el territorio que también se plantea en la novela de Alegría. 
Para abordar imaginarios del mundo rural en el cine peruano parto desde dos perspectivas de análisis; una, desde los paradigmas sobre el espacio geográfico o territorio en sí, como locaciones o lugares de narración y filmación, donde los Andes se resignifican como entorno icónico de la sierra, por ejemplo, asumidos desde una verticalidad propia de la iconografía quechua; y dos, desde sus personajes, es decir, desde los habitantes que pueblan esas ficciones: masas, héroes sin rostro o protagonistas en medio de esta búsqueda identitaria desde su inmersión en la vida en comunidad. Ambas me permiten indagar sobre el sentido de lo comunitario de los Andes, donde se "expone a los sin nombre", influido por las alturas y por las condiciones de vida o de producción.

\section{Más allá del indigenismo}

En este cine de referente andino, donde prima una mirada exógena sobre el mundo rural, surgen motivos, paradigmas y paradojas bajo la influencia o sublimación inevitable del indigenismo literario o artístico, pero también de los movimientos de izquierda, obreros y sindicalistas de los años setenta. $Y$ aquí menciono a Henry Favre, ya que la construcción de estos imaginarios del mundo rural encuentran asidero en estereotipos que se han vuelto lugares comunes a partir de los rezagos del movimiento indigenista de años anteriores, pese a que en la época en que Figueroa hizo su película ya había perdido vigencia: "la fuerza del indigenismo no reside en la persistencia más o menos considerable de valores culturales indígenas en las sociedades latinoamericanas. Depende de la significación simbólica que esos valores puedan adquirir dentro de ellas" (Favre, 2007, p. 13). Así, esta significación simbólica sobre el Ande, reflejada en algunos pasajes tanto de la segunda novela de Ciro Alegría (publicada en Chile en 1939) como de la película de Luis Figueroa, permite establecer correspondencias de estructuras de sentimientos distintas, dos generaciones y sensibilidades disímiles en torno al Ande y sus habitantes, y dos lecturas, una narrativa y otra visual, que también permite detectar ausencias dentro de este imaginario.

Uno de los lugares comunes de este universo simbólico del mundo rural aparece en Los perros hambrientos como la dicotomía campesino pobre/hacendado rico, y que se vuelve raíz de otras analogías similares: indios rebeldes frente a gamonales criollos que viven tranquilos, pasado ancestral frente a la herencia colonial vista como avance o reflejo de lo moderno (quizás más explícita en la novela) y la comparación campesinos/perros ovejeros. Pero también asoma otro tipo de analogía: la masa frente al yugo del patrón, furibunda, hambrienta, oprimida, que toma la justicia con sus propias manos, y anónima a la vez, a pesar de que haya personajes líderes, puesto que lo que prima es la idea de comunidad, el grupo y sus prioridades. 
Estos "sin nombre" que viven en comunidad, según Georges DidiHuberman, lucen expuestos, visibles, como no había sucedido antes en el cine peruano. Los personajes del Ande aparecen lejos de ser simples figurantes (a diferencia de los danzantes de Kukuli, los habitantes retratados en sus celebraciones como en los cortometrajes de la llamada Escuela del Cusco, o como los lugareños en pleno festejo del Tiempo Santo en la posterior $\mathrm{Ma}$ deinusa de Claudia Llosa) y más bien asumen un rol más activo:

los pueblos son hoy más visibles unos para otros de lo que nunca lo fueron. ¿No son ellos el objeto de todos los documentales, todos los turismos, todos los mercados comerciales, todas las telerrealidades posibles e imaginables? También nos gustaría poder significar con esta frase que los pueblos están hoy, gracias a la 'victoria de las democracias', mejor 'representados' que antes. Y sin embargo, se trata de exactamente lo contrario, ni más ni menos: los pueblos están expuestos por el hecho de estar amenazados, justamente en su representación -política, estética- e incluso, como sucede con demasiada frecuencia, en su existencia misma. Los pueblos están siempre expuestos a desaparecer. (Didi-Huberman, 2014, p. 11)

Es decir, pese a esta visibilidad, a esta irrupción tanto desde la literatura como en el cine, esta exposición de los pueblos, abstrayéndolos de la simple masa, intenta cobrar otra dimensión pero al final de cuentas no escapa al lugar común de ser un pueblo invisible, medido desde la perspectiva de su condición frente al gamonal y su ser colonizado. Si bien hay una intención de replantear la mirada sobre lo colectivo, esta resulta fallida. Si en la película de Luis Figueroa, como en la novela de Alegría, los campesinos y sirvientes tienen por lo menos una posición protagónica o activa dentro de la narración, extrayéndolos así de la simple masa (que pasa por momentos en Kuntur Wachana, por ejemplo), no pueden escapar del todo de esa carga simbólica que arrastra como penitencia el mundo andino como ámbito de lo premoderno, arcaico o retrógrado. Quizás en Todas las sangres, la novela de José María Arguedas que también fue llevada tardíamente al cine por el francés Michel Gómez en 1987, los personajes abren una posibilidad para entender el contexto de los Andes con menos pesimismo, ya que se abre paso el espíritu de transformación desde lo mestizo y desde la revolución social teniendo como telón de fondo unas montañas que dan vida a nuevas formas económicas, que los libera y restablece.

\section{Definición del cine sobre el mundo rural}

Raymond Williams señala que las novelas son comunidades conocidas, ya que se conforman de agrupaciones de sentido asequibles al destinatario. Cuando Ciro Alegría organiza su relato no solo utiliza un lenguaje asequible cuando se quiere evocar al quechua, sino que emplea una metáfora 
sencilla para construir antípodas feroces sobre la vida de los campesinos bajo el yugo del hacendado: la figura del hombre y el perro. Más allá del entorno descrito, la pobreza, las relaciones comunitarias de los personajes, lo que Alegría propone es una lectura sobre la naturaleza humana y su raigambre instintiva con la tierra a la que pertenece pero desde una metáfora animal para insertarla en un ámbito de lo comunal como antónimo del individualismo burgués:

¿Raza? No hablemos de ella. Tan mezclada como la del hombre peruano. Esos perros esforzados que son huéspedes de la cordillera andina no se uniforman sino en la pequeña estatura, el abundante pelambre y la voz aguda. Suelen ser plomos, como negros, rojizos, bayos o pintados. (...) Esta especie de perro, a la que se juzga desaparecida, seguramente late aún en el can de hoy, mestizo como su dueño, el hombre. Ancestros prehispánicos y nativos se mezclaban en Wanka y Zambo, tal como en el Simón Robles y toda la gente atravesada de esos lados. (Alegría, 1973, pp. 22)

Para el escritor, los perros no eran animales de campo o domésticos como cualquiera, sino que representaban al mestizaje, la mezcla que los relaciona a la vez a sus amos, los habitantes de Cañar. Los perros devenían en la figura de lo mestizo, pero que vive necesariamente en manada, como el hombre en comunidad.

Esta colectividad conocida o cognoscible, a partir de lo doméstico del mundo animal, que emplea Alegría es recogida por Luis Figueroa al adaptar la novela, ya que mantiene este hilo narrativo que va comparando la vida y suerte de los perros con la de los hombres ante los hacendados. Los perros son criados junto a la masa, y son "entrenados" para ser ovejeros y apoyar en las labores con el ganado. Apenas se ve alguna imagen feliz entre los animales y los gamonales. No es necesario, ya que no existe ningún vínculo afectivo que los una. Los perros son como los campesinos en ese sentido, y este espíritu de la novela no se ve recreado con habilidad en la película. Esta comunidad conocida queda establecida de manera empática y bajo algunos elementos del melodrama fácilmente reconocibles en el espectador/lector. Sin embargo, lo no conocido, lo que se ofrece a descubrir bajo el ojo del narrador omnisciente y de la puesta en escena en el caso de la película, es cómo este imaginario de lo animal se inserta en este tejido de relaciones dicotómicas de campo versus hacienda, de campesinos versus amos, de sierra versus el fantasma de Lima.

Williams señala que

En la ficción de la ciudad, la experiencia y la comunidad serían esencialmente opacas; en la ficción del campo, especialmente transparentes. Como primera concepción, este contraste resulta útil. No caben dudas, por ejemplo, de que la identidad y la comunidad, como marca de percepción y de valoración, se hacen más problemáticas a medida que aumenta la escala y la complejidad 
de la organización social característica. (2001, pp. 215)

Establece así una dicotomía en torno al campo donde la experiencia luce transparente, simple, sencilla, hay una relación cara a cara, directa, mientras lo urbano se va complejizando de acuerdo al modo en que son representados poderes políticos, la división del trabajo, la vida social cosmopolita. Indica que una comunidad se vuelve conocible, no solo al graficar o transmitir su propia realidad -como pretende el cine de denuncia de Figueroa o Federico García, por ejemplo-, sino desde aquello que necesita ser conocido y que cobra vida bajo el ojo de aquel que observa y nombra. Poner en escena la perturbación rural hasta ese momento excluida o borrosa es un deseo cumplido tanto en la novela como en la película, sobre todo si en lo literario se plasmó un cambio en las orientaciones temáticas, argumentales, estilísticas, lingüísticas para narrar las inequidades propias de la condición de ser andino o campesino. $\mathrm{Y}$ algo de eso recoge Figueroa, sobre todo porque debe ser la primera vez en el cine peruano que se establece una posibilidad de representación de lo simbólico sobre la naturaleza del hombre en el Ande libre de recovecos estéticos o artificios telúricos o costumbristas, aunque su puesta en escena refleje irregularidades en la expresión misma del lenguaje cinematográfico, y que asumo como consecuencia de una producción precaria y a un instinto vedado por darle mejor salida a las escenas.
Este proceso de llevar a la pantalla comunidades de los Andes se describió a inicios de los ochenta como parte de un cine andino o un cine campesino. Este término fue usualmente usado para referirse a películas que tenían en común historias de injusticias en la sierra; sin embargo, no reflejaban una conjunción ideológica, y menos alguna suerte de propuesta estilística cohesionada. Más bien fueron películas hechas por directores que radicaban en capitales de provincias, desvinculados realmente de las comunidades que querían representar, pese a la identificación, y en el marco de la Ley de Fomento a la Cinematografía, ley 19327, dada en el gobierno de Velasco Alvarado. En realidad, ambas denominaciones permitieron visibilizar una alternativa ante el cine limeño o urbano. Pero esta categorización por oposición no ayuda a establecer la complejidad de la producción misma del cine en un país como el Perú. Así como la actual categoría de cine regional no refleja las características de producción, estilos, tendencias que surgen fuera de Lima. Así, llamar cine campesino o andino no permitió en su momento mostrar la naturaleza exacta de un cine de particularidades y de motivación realmente política. Sin embargo, pese a varias similitudes temáticas, lo que más une a este tipo de cine político sobre el Ande es su modo de producción: precariedad técnica, bajos costos, participación de la comunidad y dirigentes tanto en los aportes para hacer el filme como en la 
actuación, y todas las escenas filmadas en locaciones reales apostando por un estilo a veces documental. Esta comunidad transparente que define Williams aparece así no solo en la representación, en el discurso del filme, como algo inherente a la visión y nostalgia del cineasta, sino en el modo en que se hizo, con tintes de lo comunal, de ese cara a cara, aunque realmente fuera solo una simulación. Por ejemplo, Kuntur Wachana fue realizada con recursos de una cooperativa agraria, mientras que Los perros hambrientos o Laulico se hizo con la participación de los mismos habitantes de las zonas donde se rodaban, y en ellas primó un asunto de representatividad o de cuota de cine "directo". Si se tenía que contar una historia sobre el Ande, tenía que ser con la participación de los mismos comuneros y dirigentes. Si se rompía este principio, se disolvía la cuota de lo real.

Por ello, más que hablar de un cine campesino o andino prefiero usar la categoría de cine sobre el mundo rural, que permita hacer énfasis en la construcción de imaginarios y representaciones, en estas comunidades conocibles, dentro de todo ese territorio, que permita indagar en estas significaciones simbólicas tanto en Kukuli como en Madeinusa, en La boca del lobo como en La última noticia, puesto que remiten a un efecto propiciado por el entorno y el territorio y por un proceso largo e inconcluso de colonización y subyugación política y social. Y así se deja de lado así un asunto de representatividad o legitimidad a partir de los sujetos en sí, lo que no ha estado claro en los filmes, sino más bien condicionados por el espacio en que viven los personajes.

\section{Los perros hambrientos: sin necesidad de aludir al mundo mítico}

En el mundo de Los perros hambrientos, que replica literalmente muchos pasajes de la novela homónima de Ciro Alegría, no hay necesidad de acudir al mito, a los apus, a los maestros de saberes ancestrales, porque hay una simpleza narrativa y estética en la representación vertical entre el patrón y los campesinos. Una verticalidad que ordena el mundo y sin cuestionamientos. Si los gamonales pretenden conservar sus tierras y su poder sobre los indios como sirvientes, el clima, con su sequía e infertilidad, va creando las condiciones para que este sistema servil se mantenga. No hay escape en el mundo que crea Figueroa. Sin embargo, a diferencia de otros filmes peruanos ambientados en los Andes (que se vuelven entornos para no vivir, como pasa en Madeinusa [2006] de Claudia Llosa, La prueba [2006] de Judith Vélez, en el episodio andino de Climas [2014] de Enrica Pérez o en $\mathrm{La}$ última noticia [2015] de Alejandro Legaspi), aquí los campesinos y sus familias quedan sometidos a la autoridad del clima, porque no existe manera de romper ese vínculo natural que los enclaustra y empobrece. No pueden escapar como el personaje de Magaly Solier 
en Madeinusa, ni elegir en medio del horror senderista como pasa con los personajes del filme de Legaspi. Y tampoco dentro de lo propuesto en la película de Figueroa asoma una conciencia sobre ese mal que cae sobre ellos.

Por ejemplo, en Kukuli es claro el uso del espacio de la montaña desde su verticalidad, sumando así a un imaginario de las alturas: las escenas iniciales muestran a la protagonista descendiendo la puna, pero también acariciando una alpaca como una plena descripción del arriba y abajo como patrón espacial. Mientras que en Los perros hambrientos la ubicación es horizontal, puesto que no hay viaje o cambio de lugar de por medio. Los personajes se ubican en un lugar predeterminado, y vivirlo es parte del sino que los gobierna.

En el ensayo "Cine y geografía", de Agustín Gámir Orueta y Carlos Manuel Valdés, se indica que

...a pesar de la intensidad con la que son retratados determinados lugares, incluidos los recientemente incorporados a este imaginario colectivo, no está de más recordar que el conjunto de las filmaciones de mayor impacto difunde una imagen incompleta de un globo terrestre en el que sobresalen algunos territorios que centran la atención de las cámaras frente a otros que quedan como grandes vacíos. Se trata de lo que podríamos calificar como "lugares olvidados" por el cine. Son paisajes, ciudades y territorios que no han sido seleccionados y cuya imagen es desconocida por el espectador, incluso en los casos en los que está físicamente próximo a él. (Gámir Orueta y Valdés, 2007, p. 169)

Es inevitable denominar como "lugares olvidados" a los Andes hasta determinado periodo en el cine peruano, sobre todo porque sí hubo cortometrajes y noticiarios que apuntaron a mostrar, sobre todo a los limeños, este espacio pero con un afán informativo, ilustrativo, ya ni siquiera turístico. Y no es sino hasta los trabajos de la Escuela del Cusco que los Andes aparecieron bajo una predominancia geopolítica, como entorno de poder alterno a la capital, y esto se refleja en los filmes de Figueroa o García, como espacio de lucha de poderes, con desventajas e injusticias.

Por otro lado, más que ubicar el paradigma sobre el mundo rural en un entorno de discusión política o geopolítica en el marco del indigenismo en las primeras décadas del siglo $\mathrm{xx}$, es idóneo aplicar lo que Mirko Lauer denominó como indigenismo 2: el indigenismo cultural-creativo (literario, plástico, arquitectónico o musical) que se desarrolló entre 1919 y mediados de los años cuarenta. Tampoco quisiera dilatar mi análisis en la contribución del indigenismo político o el regionalismo literario a la construcción de una idea de lo nacional a partir de la ruralidad, menos aún si en el cine peruano no hubo casos específicos (quizás Kukuli de Luis Figueroa sea el ejemplo más inmediato para hablar de telurismo o costumbrismo inspirado en las narrativas sobre el indio), pero sí 
creo que el indigenismo 2 resulta más exacto para señalar el tema de la significación sociocultural que aparecieron como referentes de verosimilitud en este tipo de filmes (Lauer, 1997). En Andes imaginarios sostiene que el indigenismo 2 fue la construcción ideológica de una cultura criolla que deseaba expandir su radio de acción hacia esa zona inexplorada y difícil de controlar por el Estado que es lo autóctono en la cultura. Los artistas, escritores, músicos, representantes del indigenismo cultural-creativo peruano se centraron en "una fantasía de capas medias urbanizadas en ascenso hacia una modernidad conflictiva", y finalmente inviable. Recuperar su idea de lo autóctono mediante dispositivos ajenos a los entornos que describían fue "un acto restaurador, ético y nacionalista" (como la novela de inspiración modernista, por ejemplo). Por eso, me parece que la manera en que se realizó, por ejemplo, Kukuli tuvo mucho que ver con los rezagos del modo en que los artistas y literatos del indigenismo 2 contemplaban el universo andino: cineastas que no eran campesinos ni indígenas sino pertenecientes a la clase media cusqueña, una visión telúrica del Ande, recreación de un entorno aparente libre de problemáticas agrarias, sin oprimidos ni racismo, y una apuesta clara por la representación de lo mítico (Juan el Oso, claramente). Sin embargo, esta exotización y apuesta por lo mítico, al final de cuentas, queda fuera de Los perros hambrientos, que muestra un viraje conceptual opuesto en torno a lo indio y su dramática situación precarizada y oprimida desde un tipo de realismo y halo de intención testimonial.

El filme Los perros hambrientos comienza con unos paneos que van siguiendo a Simón, quien trae unos cachorros a Antuca, cuya primera acción es llevar a los perritos a que sean amamantados por una oveja y crear así una cercanía que se verá fortalecida para el trabajo en el campo. Luego, el cineasta va describiendo el interior de la hacienda del patrón, donde se celebran cenas en un ambiente tranquilo. Sin embargo, al contar con la participación de actores no profesionales, los mismos habitantes del lugar, existe un aspecto declamativo en los diálogos que evita cualquier ambición de realismo o de incorporación de lo testimonial. Los personajes dicen las frases como si estas hubieran sido memorizadas, y la naturalidad con que las frases eran leídas en la novela se pierde completamente en la adaptación por esta falla en la dirección de los actores.

Figueroa elige un estilo de puesta en escena que traduce la sequedad de la puna, a través de escenas de planos diversos y secuencias breves, a ritmo de quenas o zampoñas, en las que casi no hay espacio para la contemplación, la indagación etnográfica o la descripción costumbrista. En esta premura narrativa, que evita recovecos simbólicos basados en ritos o mitos, Figueroa apuesta por seguir de modo fiel el espíritu de la novela: optar por la verosimilitud del realismo, pese a 
los problemas en la puesta en escena que menciono.

El crítico Balmes Lozano señaló que

La constante del cine indigenista no es la exterioridad, el exotismo, o la incipiente formalización que tanto disgusta a los críticos. Más bien la constante principal reside en la función instrumental, es decir, en servir como vehículo para la denuncia social, la propaganda política o la protesta popular. (1984, pp. 186)

Y esta finalidad está latente en Los perros hambrientos, pero con una finalidad distinta a la planteada en el cine de Federico García, ya que hay una intención humanista en la novela de Alegría que Figueroa mantiene, antes que convertir a su filme en un instrumento de propaganda o protesta, ya que el mensaje sobre la reivindicación de lo andino queda soterrado.

En una entrevista hecha en 2003 por Renée Le Saint y Jean- Louis Descroix, el cineasta sostuvo que

Hay dos escenas que podemos poner en relación, en un momento sale una procesión a dar toda una vuelta para pedir la lluvia, y casi después se ve a una viejita, en su casa y que parece que está combatiendo con los demonios... Sí, efectivamente son pequeños elementos que están mostrando la supervivencia de creencias. La viejita está ahuyentando a los malos espíritus que han traído la sequía, y la gente de la comunidad va de procesión a hacer rogativas para que la Virgen, la madre, les ofrezca la lluvia. (Le Saint, R., Descroix, J.-L., 2003)
Sin embargo, en lo que se ve en el filme, esta comparación que menciona Figueroa no queda clara. Hay varias escenas en Los perros hambrientos que remiten a destacar este lado de creencias y de fe, para demostrar el sincretismo religioso, sin embargo la puesta en escena no permite el reconocimiento claro de esta intención.

\section{El hombre y el perro: vida, pasión y muerte bajo la lluvia}

En un pasaje de la novela, el narrador reflexiona:

El animal ama a quien le da de comer. Y, sin duda, pasa lo mismo con ese animal superior que es el hombre, aunque este acepte la ración en forma de equivalencias menos ostensibles. De allí el antiguo gusto por los amos. Y seguramente el sentimiento de la querencia no es otra cosa que el recuerdo físico, la adhesión primaria a la tierra, el agua, el aire, y todas las cosas que hicieron para vivir. (Alegría, 1973, pp. 135)

Pareciera que antes que prime un imaginario de lo telúrico, que sí tiene Kukuli, o sobre las festividades, tal como aparecen en Yawar Fiesta o Kuntur Wachana, en Los perros hambrientos sí existe esta fidelidad a la novela en cuanto analogía animal casi literal, lo que evita la inclusión de lo costumbrista a cambio de una mirada más "naturalista". No hay necesidad de lo ritual para definir la identidad de este grupo de campesinos en opresión. 
Hay una escena donde apenas se ve el goce de los campesinos bebiendo y cantando, sin augurar la situación de crisis que se asoma. Sin embargo, la catarsis que permite el alcohol y la conversación apenas dilucida esta insatisfacción por la condición de sumisión ante el hacendado: los bandoleros hablan de venganza, pero no reflexionan sobre la misma condición de opresión que los ha llevado al robo. Luego este tipo de celebraciones austeras, libres de parafernalias o reminiscencias a danzas coloridas y mascaradas, y que no aparecen en la novela, son comparadas con cenas, misas católicas o reuniones de los hacendados, donde prima un entorno de lo masculino, espacio de hombres letrados, con dinero o ejerciendo algún cargo público, que deciden, ordenan y dirigen. La parábola animal casi no necesita del costumbrismo, sino que más bien aprovecha estas breves reuniones para afirmar una idea de separación de clases.

En la novela de Ciro Alegría, el punto de vista que prima es el de los perros y permite realizar la analogía con los personajes de Cañar. Estos animales, Güeso, Zambo, Wanka y Pellejo, protagonistas reales en esta historia, van dibujando en sus afrentas los efectos de una sequía asesina, donde la supervivencia del hombre en tiempo de crisis solo es comparable con la lucha instintiva por vivir.

Bajo una perspectiva narrativa similar a la que emplea Jack London en
El llamado de la selva, Alegría va describiendo capítulo a capítulo el devenir de estos animales, tomando quizás el relato de la vida, pasión y muerte de Cristo como analogía sobre la naturaleza del mal y la impasividad del hombre ante la adversidad a modo de sacrificio. Se muestra una existencia que depende de la voluntad del hombre, ya sea este comunero, arriero, bandolero o hacendado. Pareciera que hubiera una búsqueda por humanizar este estado de los perros bajo el albedrío de los campesinos, a la manera de los horrores a los que es sometido Baltazar en la célebre película de Robert Bresson, sin embargo, la dispersión en la adaptación, y la falta de un norte estilístico en la puesta en escena convierten esta posibilidad en lejana.

La suerte que corren los perros (hambruna, violencia, muerte) es similar a la que viven los campesinos. Si los perros no pueden librarse de la voluntad y el poder de los hombres que los rodean, los campesinos viven esa misma esclavitud por parte de los gamonales, quienes los dominan $\mathrm{y}$ disminuyen.

En parte de la entrevista que recuperé líneas arriba, Figueroa responde sobre los dos momentos en que los campesinos y el hacendado se enfrentan y que los entrevistadores consideran como representativos de las relaciones que existen entre el patrón y los campesinos. Figueroa revela que estos problemas que él recrea ambientándolos en los años treinta 
del siglo pasado, previos a la reforma agraria, aún persisten.

Para mí, realmente, Los perros hambrientos significaba la novela del equilibrio entre dos universos, la naturaleza y el hombre. Y el personaje invisible que va a definir el destino del hombre, de los pueblos y de los animales en la naturaleza es la sequía. Agudiza los conflictos tradicionales del mundo andino entre hacendados y campesinos y también otros sectores del poder como son los notables, los gendarmes, el poder militar, el poder político, y también los que están fuera de la ley, los bandoleros que roban el ganado, que roban los bienes de los hacendados para ofrecérselos a los pobres, a los campesinos.

El cineasta plasma fielmente este conflicto, pero lo hace basado en oposiciones simples, aunque conservando la figura de la sequía en su capacidad destructora:

divorcia la relación del hombre con la naturaleza y agudiza los conflictos sociales de clase. Y en este sentido, los perros hambrientos vienen a simbolizar la tragedia humana: los campesinos explotados tienen que emigrar a otras haciendas para buscar algo de alimento para sobrevivir. Es allí donde se agudizan los conflictos que desencadenan muchas veces en tragedia, que es una de las secuencias finales de la película.

Sin embargo, esta migración no sucede en la película, ya que los personajes que quedan tras la masacre se ven protegidos ambiguamente por la lluvia buena, porque el fenómeno esperado que los salvaría de la sequía llega tarde y sin poder transformar nada.

Cuando el narrador en la novela de Alegría asevera que "El animal ama a quien le da de comer", Figueroa extrapola esta afirmación en una secuencia que también aparece casi fiel al texto: los campesinos que sufren una sequía devastadora por meses, que los deja sin comida ni agua, acuden a la hacienda del patrón a pedirle comida. Las súplicas, llantos, rezos no conmueven al hacendado, quien ante la insistencia y furia comienza a disparar, con la ayuda incluso de su hijo pequeño, contra la masa, dispuesta al ataque a punta de machetes. Estos "perros hambrientos" son acorralados y liquidados, sin oportunidad. Esta secuencia se centra en una demanda desesperada por alimento, para atenuar una situación de pobreza extrema propiciada por la naturaleza. Sin embargo, ni en la novela ni en la película se hace explícita la situación de esclavitud y de opresión como un problema social y económico rezago de la herencia colonial. Es como si la premisa "El animal ama a quien le da de comer" se volviera en la justificación sentimental de una tara de podredumbre social. Si el amo diera de comer a sus campesinos, que labran y cosechan la tierra que tiene un solo dueño, el orden seguiría su curso con normalidad. Esta certeza de la novela es repetida por Figueroa.

En La utopía arcaica, Mario Vargas Llosa señala que según la óptica del pensamiento nacionalista se cree que 
... mientras más allegada sea una persona a un pedazo de tierra es más auténtica y humana, y mientras menos, más artificial y malvada. El indio comunero, que nace y muere dentro del microcosmos de su comunidad, preservando su lengua, sus cantos, los ritos ancestrales y trabajando la misma tierra de sus antepasados, es naturalmente virtuoso y de una humanidad prístina. Pero, si cambia, se vuelve vulnerable y puede perder su alma. (1997, p. 260)

Es probable que esta no haya sido la intención del final de Los perros hambrientos, sin embargo esta lectura permite visibilizar una contradicción: antes que ver a los campesinos como seres con futuro en los Andes, se les ve condenados, sin tener la posibilidad de Madeinusa o de Alonso de La última noticia: la de huir.

\section{Representación de la masa}

Hay una línea de tiempo clara en la novela y que la película recoge fielmente, que va desde el nacimiento de los perros ovejeros hasta su dispersión o desaparición. Este crecimiento apenas tiene un paralelo claro con la aparición de los personajes humanos, tanto en la novela como en la película. Los habitantes de Áncash en la novela son "adaptados" a los personajes de Cajamarca en la película sin sufrir un cambio significativo. Se conserva la idea de Alegría de mantener este sentido de comunidad, sin darle un peso especial a un personaje determinado.
Si en la novela no existe el reconocimiento claro de un "protagonista" es porque a Alegría le interesa trabajar a punta de analogías la idea de manada, de grupo de perros vigilantes de ovejas, y a la vez de campesinos forzados a hacer frente a la adversidad en unidad. Aparecen los personajes de Simón Robles, Mashe, Jacinta, Julián Celedón, casi todos descritos desde la distancia del testigo impasible, como la mirada de los canes ovejeros que acompañan en la puna, las cosechas, la sequía y las muertes. Así uno a uno se va volviendo masa hasta el enfrentamiento final con don Cipriano, el hacendado. En esta progresión narrada en clave de fresco, en la que no se llega a definir algún protagonismo, la sequía aparece como la encarnación real del mal en esa tierra que pertenece a medias al campesino. Esta "adhesión primaria a la tierra", entendida como un apego innato, se ve traicionada por la furia de la naturaleza, traducida en una sequía de meses que vuelve a la puna en un desierto mucho más hostil.

Benedict Anderson señala que la nación "se imagina comunidad porque, independientemente de la desigualdad y la explotación que pueda prevalecer en cada caso, la nación se concibe siempre como un compañerismo profundo, horizontal" (1993, pp. 25). Esta premisa queda patente sobre todo al final de la película al establecer un entramado simbólico que remite a una colectividad pareja en su desgracia: la lluvia que todo lo cubre y limpia, aunque el entorno del gamonal 
permanezca intacto. La imposibilidad del cambio.

\section{Conclusiones}

Recupero una frase de La boca del lobo (1988), dirigida por Francisco Lombardi y que permite recoger una sensibilidad en torno a los Andes: "A simple vista Chuspi no me pareció ni mejor ni peor que tantos otros pueblitos perdidos que hay en la sierra. La misma tristeza, la misma miseria, el mismo estado de abandono que habíamos visto en todo el camino". Si bien el contexto en que el personaje soldado de este filme, sobre una incursión militar en tiempos de ataques de Sendero Luminoso, es distinto al que hace referencia la película de Luis Figueroa, comparte este sentimiento de desolación ante una situación inalterable.

Esta narración en negativo, es decir, que busca llamar la atención del espectador para crear una demanda de cambio a partir de componentes de melodrama, de tragedia que busca conmover, parece que no logra su objetivo político. Más bien con el paso del tiempo queda evidente que el filme sí fue un instrumento pero que no cumplió un rol movilizador, sino más bien colaboró a cimentar una imagen de los Andes y la ruralidad donde es imposible vivir, pese al halo de esperanza reflejado al final de Los perros hambrientos.

En la escena final de la película se ve a un campesino resignado, sin resistencia, bajo la fuerte caída de lluvia que todo lo baña y purifica; sin embargo, su condición de subordinado y olvidado es la misma que al inicio del filme: la única sutil diferencia es que se ha roto la comunidad, se ha quedado solo tras la masacre, exactamente igual de desprotegido que la perra Wanka que acaricia y abraza.

\section{Referencias}

Alegría, C. (1973). Los perros hambrientos. Lima: Peisa.

Anderson, B. (2007). Comunidades imaginadas. México, D.F.: Fondo de Cultura Económica.

Didi-Huberman, G. (2014). Pueblos expuestos, pueblos figurantes. Buenos Aires: Manantial Texturas.

Favre, H. (2007). El movimiento indigenista en América Latina. Lima: Instituto Francés de Estudios Andinos.

Gámir Orueta, A. y Valdés, C. M. (2007). Cine y geografía. Espacio geográfico, paisaje y territorio en las producciones cinematográficas. Boletín de la A.G.E., (45), pp. 157-190.

Lauer, M. (1997). Andes imaginarios. Discursos del indigenismo-2. Cusco-Lima: Centro de Estudios Regionales Andinos Bartolomé de Las Casas-Sur.

Le Saint, R., Descroix, J.-L. (2003). Luis Figueroa, un maestro del cine andino [en línea]. Entrevista. Disponible en http://crdp2.ac-rennes.fr/puka/ 
html/luis_figueroa. [Consulta: 20 Vargas Llosa, M. (1997). La utopía arcaide mayo de 2014]. ca. José María Arguedas y las ficciones

Lozano, B. (comp.). (1989). El cine pedel indigenismo. Lima: Alfaguara.

ruano visto por críticos y realizadores. Williams, R. (2001). El campo y la ciuLima: Cinemateca de Lima. dad. Buenos Aires: Espacios del Saber 16. Paidós. 
